This is the author's penultimate, peer-reviewed, post-print manuscript as accepted for publication. The publisher-formatted PDF may be available through the journal web site or, your college and university library.

\title{
Making Tacit Knowledge Explicit: The Ready Reference Database as Codified Knowledge Mark Stover
}

\section{Manuscript Citation:}

The following APA style citation may be used to reference this manuscript:

Stover, M. (2004). Making tacit knowledge explicit: the ready reference database as codified knowledge. Retrieved from http://scholarworks.csun.edu

\section{Version of Record Information:}

Citation: Stover, M. (2004). Making tacit knowledge explicit: the ready reference database as codified knowledge. Reference Services Review, 32(2), 164-173.

Copyright: Copyright $\odot$ Emerald Publishing Group

(DOI): 10.1108/00907320410537685

URL: http://www.emeraldinsight.com/0090-7324.htm

This item was retrieved from CSUN ScholarWorks, the open-access, institutional repository of California State University, Northridge. http://scholarworks.csun.edu 
Making Tacit Knowledge Explicit: The Ready Reference Database as Codified Knowledge

\title{
By Mark Stover
}

\begin{abstract}
This article describes the process of knowledge transformation (from tacit to explicit to codified knowledge) in organizations. The article proposes that much of the knowledge held by reference librarians is tacit knowledge that needs to be made explicit and formalized. The Web-based ready reference database at San Diego State University is analyzed as an example of the process of knowledge conversion in library reference services.
\end{abstract}

\section{Keywords}

Knowledge Management; Tacit Knowledge; Explicit Knowledge; Codified Knowledge; Ready Reference Database 


\section{Introduction}

How does a reference librarian with little knowledge in a particular field answer reference questions from that discipline? How does a new librarian quickly assimilate new knowledge about the reference sources, practices, and policies that are particular to her library? How do reference librarians remember organizational policies that patrons ask about or that must be integrated into reference desk practice? How do librarians keep up with the idiosyncrasies of subscription databases that seem to change daily? The answer to all of these questions lies in the knowledge management practice of converting tacit knowledge into explicit, codified knowledge.

Tacit knowledge refers to the undocumented and unarticulated (but nevertheless important) knowledge held by practitioners (McInerney, 2002). It is also known as “inarticulate intelligence,” “collective wisdom,” or “elusive knowledge.” The phrase “tacit knowledge” was coined by Michael Polanyi (1958; 1966), an influential philosopher of epistemology, but in recent years it has been used by management theorists as a key piece in the process of knowledge management (Firestone and McElroy, 2003). Tacit knowledge is contrasted with explicit knowledge, which is expressed knowledge that is communicated to others. When explicit knowledge is documented, it becomes “codified.” Codified knowledge is usually quite structured and appears in written reports, databases, and other media. 
This article describes the process of knowledge transformation (from tacit to explicit to codified knowledge) in organizations. The article proposes that much of the knowledge held by reference librarians is tacit knowledge that needs to be made explicit and formalized. The Web-based ready reference database at San Diego State University is analyzed as an example of the process of knowledge conversion in library reference services. The knowledge management model presented here may be used by other libraries to provide more efficient and effective reference service.

\section{Tacit Knowledge in Organizations}

Theories of tacit knowledge often are presented in the context of "knowledge management.” While knowledge management is usually practiced in an environment distinct from the traditional library setting, there are nevertheless many similarities between the knowledge management ideas of the business world and the ways that librarians handle information.

Tacit knowledge is intuitive and practice-based, which makes it both valuable and difficult to pass on to others. Schon (1983) called this "knowing in practice." When a person has a great deal of knowledge about something, her expertise allows her to intuitively find answers to a problem much faster than a colleague whose area of expertise is in a different area (Baumard, 1999). 
Tacit knowledge is community centered (Blair, 2002). Groups often “own” knowledge, "based on the collective experience, insights, and contexts of individuals and groups of knowers," in a better and different way than any one individual can (Short, 2000, p. 354).

\section{Articulating Tacit Knowledge}

While knowledge management theory is not foremost on the minds of most reference librarians, the process of knowledge conversion should nonetheless be an important part of every librarian’s work. "Sharing information by making it readily accessible to others” (Kesner, 2001b, p. 26) is the responsibility of each employee; librarians more than most others should recognize the importance of disseminating information.

There are many reasons why articulating tacit knowledge (making it explicit and codifying it) is crucial to the success of any organization. The same problems don't need to be solved over and over again (Shearmur, 2000). The “owner” of a particular piece of tacit knowledge does not have to be present and available in order to share this information. Once tacit knowledge is converted to explicit knowledge, the organization is in less danger of losing its "knowledge capital" when employees leave the organization. (Davenport and Prusak, 1998; Baumard, 1999; Lave and Wenger, 1991). Explicit knowledge gives permanence to previously impermanent knowledge, and it can more easily "be shared, stored, combined, and manipulated in a variety of ways” (Davenport and Prusak, 1998, p. 87). 
Knowledge management theorists believe that, in general, it is cost effective for both individuals and organizations to have access to explicit knowledge (Baumard, 1999). Information is more easily accessible when tacit knowledge has been converted to explicit knowledge. It helps different parts of the organization communicate with each other more easily, and it promotes competence and efficiency in individual employees (Choo, 2000).

The purpose of the codification of tacit knowledge is not simply to facilitate retrieval of information, although this certainly is important. Beyond access, however, is the reuse of knowledge in new ways that entails reflection, criticism, learning, and ultimately the creation of new knowledge than had previously existed (Choo, 2000).

\section{The Richness of Knowledge Transfer}

Knowledge management is an ongoing procedure that refines raw information and shares it across boundaries in the organization. It is a "bottom-up" process that develops and exploits the "tangible assets and intangible knowledge resources" of the organization (Smith, 2001, p. 313). Some have described this process as "reusing intellectual assets" (Davenport, Thomas, and Desouza, 2003). 
The literature of knowledge management (Baumard, 1999; Nonaka, Konno, and Toyama, 2001; Choo, 1998) describes the knowledge transfer process as including the following sequence of steps:

1. tacit to tacit (often called "socialization," which occurs through apprenticeship, mentoring, or collegial relations; this step has also been described as "implicit learning” or “learning by doing”);

2. tacit to explicit (often called “externalization” or "articulation;” this step includes knowledge that is usually written down or communicated in some permanent or semi-permanent way; stories, narrative, multi-media presentations, group reflection, conversations, emails, and memos are all examples of this type of knowledge transfer);

3. explicit to explicit (often called “combination,” usually through a standardized and systematic procedure; an example would be a computer database or an expert system);

4. explicit to tacit (often called "internalization," which results in the distribution of knowledge throughout the organization and beyond; this often comes through active participation and repetition). 
According to knowledge management theorists (Zack, 1999; Choo, 2000; Kesner, 2001b), there are generally three separate but related steps in codifying knowledge once it has been made explicit. First, the organization should create "warehouses” of explicit knowledge, a process known as internal codification (Choo, 2000). These materials can be collections of paper documents, links to web pages, rough drafts in electronic form, email messages, or notes from discussions or interviews. Second, the organization should create mechanisms that will refine the collected explicit knowledge, extract valuable content, and turn it into a more usable form. This step will add value to the knowledge through a taxonomy that will include controlled vocabulary and appropriate cross-referencing. Third, the organization must provide for appropriate technologies that will support this entire process. This “delivery platform” must be able to push and pull content (through subscriptions and through searchable databases) for various groups in the organization. These three steps turn raw knowledge into refined knowledge.

\section{Barriers to Knowledge Articulation}

There are a number of difficulties in making tacit knowledge explicit. Tacit knowledge is both complex and subjective. It is often embedded in an individual's intuitive personal experience, and thus is hard to formalize or communicate (Nonaka and Takeuchi, 1995; Baumard, 1999; Choo, 2000; Davenport and Prusak, 1998). It is almost impossible to observe or measure tacit knowledge, since it is in "the realm of the non-expressed" (Baumard, 1999, p. 79). 
In addition, there are often personal issues that may get in the way of articulating tacit knowledge. Employees might believe that their personal knowledge is not worth expressing. They may think that expressing their knowledge may endanger their position with the organization, either because they know too much or they don’t know enough. There may be language barriers to articulating their knowledge, or they may have forgotten what they once knew (Baumard, 1999)

Sometimes "political” problems present a barrier to knowledge articulation. Sharing knowledge may not be part of the "corporate culture” of an organization (Blair, 2002). Since knowledge represents power and privilege to many employees in an organization, some may not feel obligated to share their knowledge with anyone other than those in the immediate environment (Baumard, 1999). This may seem rational from the "local” (personal) perspective but is clearly counter productive from the "global” (organizational) perspective (Stenmark, 2002).

Baumard (1999, p. 11) refers to the problems that result from a knowledge-segmented organization as "the tyranny of the local environment." Each segment of an organization has its own knowledge store, and may choose to share (or not share) its knowledge with other segments of the organization. Sometimes this information isolation occurs for political reasons, but more often it exists due to the absence of a compelling philosophy of explicit knowledge sharing in the organization. Employees usually act in ways that appear to serve their best interests or the interests of their particular segment of the 
organization. Very rarely do these "locally-motivated" actions result in the sharing of knowledge through the tacit-explicit continuum.

Organizations tend to be informal, competitive, and "ceremonial” in the ways that they share knowledge across division lines (Baumard, 1999). The informality often leads to a great deal of tacit knowledge "falling through the cracks" and never shared with other segments of the organization. The competitive nature of organizations leads to political rivalries that discourage making tacit knowledge explicit, and the ceremonial aspects of organizations often results in a rigid adherence to "the way we’ve always done things" and thus a resistance to change.

The process of knowledge articulation is not always a pleasant one, since sometimes content experts are not willing to share their knowledge with others (Laupase, 2003). Each individual in the organization must recognize that he is a stakeholder and that he is responsible (in some way, however small) for his role in the process of organizational knowledge creation (Kenser, 2001a).

\section{Encouraging Knowledge Conversion}

There are several ways to encourage knowledge conversion within an organization. One method of promoting knowledge transformation is to engage employees in "reflexive practice," which is "the activity of thinking about one's own actions and analyzing them 
in a critical manner, with the purpose of improving a professional practice” (Baumard, 1999, p. 96).

Formal interviews are a useful method of making tacit knowledge explicit. Outside observers can assist in the knowledge conversion process by asking employees a series of structured questions. How do you manage your knowledge? How do you interact with your environment? From where do you draw your knowledge? What knowledge gives you a major advantage? Do you know things that others in the organization do not know? (Baumard, 1999). These questions should be asked in an iterative fashion, in at least two different interviews, so that the observer can be sure (through feedback from the “expert”) that his or her observations are accurate. But the observer must be careful not to impose himself or herself as the sole "articulator of tacit knowledge,” (Baumard, 1999, p. 175) since this could result in less ambiguity (which could be good or bad) but even greater rigidity (which is usually bad). The interviewer should remember that “individuals with different cognitive styles have very different tolerances towards ambiguity” (Baumard, 1999, p. 175).

Interaction with others, as opposed to isolation, is important if knowledge conversion is to take place. Knowledge creation in an organization does not occur in a vacuum. It is shared, clarified, and recreated through interacting with others (Nonaka, Konno, and Toyama, 2001). Teams must work together in a complimentary manner and create knowledge (both tacit and explicit) through collaborative relationships, informal 
conversations, and formal information transfer (Choo, 1998). Technology must never be allowed to replace or supercede human relationships (Desouza, 2003; Hislop, 2002).

A psychologically healthy environment is crucial to a successful knowledge conversion program. For example, knowledge conversion is best performed in an organization where ideas are sharply critiqued but individuals are respected (Sternberg, 1999). A positive atmosphere that encourages knowledge sharing is extremely important (Koenig and Srikantaiah, 2000).

An organization must define itself through boundaries and categories before it can articulate tacit knowledge effectively (Zack, 1999). A database of explicit knowledge is meaningless if it does not directly relate to the work of the organization. This database must also demonstrate the context and relationships of its data if it is to successfully push and pull codified knowledge.

An obvious prerequisite to successfully formalizing tacit knowledge is identifying who the people are who have the tacit knowledge. Some organizations assign one person to handle the role of knowledge manager (e.g., chief knowledge officer), while other organizations distribute this role across the organization and assign various individuals or teams to be responsible for different clusters of knowledge (Zack, 1999). In any event, a process should be in place whereby either an individual or a team creates a matrix (or a map) that defines specific roles and responsibilities (Kenser, 2001a). 
Knowledge sharing is often more successful in informal settings than in formal ones (Dixon, 2000). Asking someone to give you advice is much easier than asking them to write it down and put it in a database, especially if that database is perceived as an impersonal structure that has no useful connection to either "real life" or to other people in the organization. Knowledge bases must provide some practical and tangible benefit to those who contribute to them.

Baumard (1999) found that there were common characteristics among successful knowledge conversion companies, including the following: resolution of ambiguity through intentional communities of practice; tacit complicity among employees; informal matrices of relationships among employees; and reliance upon collective knowledge. Knowledge must be fluid enough to be open to change and revision, but it must be rigid enough to be useful and accessible to most employees. Categories and standards assist in information retrieval, but they also "destroy subtlety and lead to reductive visions of reality” (Baumard, 1999, p. 201). Maintaining this equilibrium and balance is the key to successful knowledge conversion.

\section{Potential Problems with Codified Knowledge}

There are a number of potential problems with codified knowledge in an organization. For example, formalized knowledge must continually be evaluated so that it does not grow old and stale (Davenport and Prusak, 1998; McInerney, 2002). When the tacit 
dimension of knowledge becomes overshadowed by the explicit dimension, a "fossilization of knowledge" occurs that stifles the flow of information. Baumard (1999, p. 194) calls this “the domination of 'hard' knowledge over 'soft' knowledge," or knowledge that has become overly explicit. In some cases this can result in the suppression of other forms of knowledge that then become subservient to codified knowledge (Lave and Wenger, 1999).

Tacit knowledge that is formalized is often somewhat less versatile and renewable (Baumard, 1999). Davenport and Prusak (1998, p. 87) write that "the challenge is to codify knowledge and still leave its distinctive attributes intact, putting in place codification structures that can change as rapidly and flexibly as the knowledge itself.”

Related to the fossilization of knowledge is what some have described as the overrationalization of knowledge (Baumard, 1999). When organizations make tacit knowledge explicit and then codify it, they run the risk of de-legitimizing the evolution of knowledge and the role of socialization in knowledge conversion, potentially resulting in an undue reliance on rigid structures and formalized knowledge. Baumard calls this the “Taylorization of knowledge” (1999, p. 206).

"Thick knowledge" is the complex matrix of tacit knowledge that exists in an organization. It contains nuances that cannot be communicated through codification. Although codification standardizes knowledge in an organization, it carries the risk of employees perceiving that the codification process has transferred the complete, textured 
portfolio of thick knowledge to the new knowledge base. Everyone in the organization must understand that codified knowledge articulates and documents tacit knowledge, but it does not replicate it (Baumard, 1999).

Codified knowledge should not be thought as the "all to end all” of knowledge management. Explicit knowledge must live simultaneously with implicit learning, which "takes place largely independently of conscious attempts to learn and largely in the absence of explicit knowledge about what was acquired” (Reber, 1993, p. 5).

There are also potential political problems that may affect an organizational knowledge base that has been formalized. Articulated, codified knowledge is by definition shared and thus available to all within the organization (and, depending on the type of organization and the method of codification, also available to others outside the organization). Thus, it becomes less important as a way to differentiate between employees, since the knowledge that was once tacit and mystifying to all but one "knowledgeable" individual is now shared and freely available to all. This has many positive effects, including the leveling out of the organization, but it also may concern some "experts" within the organization who may not wish to share their knowledge lest they lose their expert status. However, as Sternberg (1999) notes, new tacit knowledge is always being created that replaces recently codified explicit knowledge. 


\section{Librarians and Tacit Knowledge}

Tacit knowledge has been demonstrated to play an important role in a variety of professions, including law, medicine, management, sales, education, and the military (Sternberg and Horvath, 1999). Librarianship can surely be added to this list. Librarians possess tacit knowledge and undocumented expertise that is critical to their work, and generally tend to be intuitive and reflective practitioners (Crowley 2001). As Choo (2000, p. 397) writes, not only are librarians and information professionals "skilled at selecting and searching information sources, [but] they also have the know-how to articulate and analyze information needs, evaluate the quality of information, extract and summarize important information, and relate and package the information found for a specific project or problem.”

Reference librarians have unique needs for the formalization of tacit knowledge. Most reference librarians work at busy reference desks or function in online environments providing digital reference service. While many reference professionals are subject specialists in one or more disciplines, most have information demands placed upon them that require a breadth of knowledge impossible for any one person to attain. It is important for reference librarians to make explicit and codify their tacit knowledge base if reference services are to be provided efficiently and effectively. In addition to current demands of the reference desk and other reference services, the wave of retirements that

promises to hit the "baby boom" generation necessitates a systematic articulation of tacit 
knowledge to ensure the prevention of knowledge loss in coming generations of librarians.

It should be remembered that libraries are communities of practice where "situational learning develops and is legitimized” (Baumard, 1999, p. 209). Communities of practice often rely on relationships and tacit socialization. Knowledge is often not readily articulated within communities of practice; thus, codification of knowledge can protect the library from losing valuable information when an individual member leaves (Wenger, 2003; Baumard, 1999; Lave and Wenger, 1991).

Knowledge isolation is a problem for many professionals (Sternberg, 1999, p. 233). Reference librarians sometimes work in pairs, but even so may often feel isolated from their colleagues. The articulation of tacit knowledge within a reference department alleviates this isolation and allows each librarian to share their acquired knowledge through a variety of means. It also solves the problem of adapting to a changing environment, where shifting Web links, altered policies, and new resources require a broad-based knowledge repository accessible to all librarians.

There are various ways that reference librarians transfer or articulate their knowledge to other librarians. Clearly, reference librarians often learn implicitly through the socialization ("tacit to tacit”) process when working with colleagues at the reference desk or through mentoring by more experienced co-workers. The "tacit to explicit" articulation process often takes place through emails, internal workshops, professional 
conferences, seminars, printed and Web-based guides, publication of books and journal articles, and informal conversations. In addition, we can expect that new technologies will yield more creative methods (Applen, 2002). A recent article advocated librarians converting Web Logs (or Blogs) into knowledge bases as part of an organizational knowledge sharing strategy (Angeles, 2003).

But reference librarians need to formalize their tacit knowledge, their non-codified explicit knowledge, and even many forms of their codified knowledge in a systematic manner. For many years the reference departments in most libraries have done just that in the form of the "ready reference file." Over the past two decades, a number of libraries have converted their card-based files (also known as “community information files”) to electronic format using database management software (Stover and Grassian, 1989; Thomas and Sottong, 1994). In more recent years, some libraries have experimented with using Web-based technologies to codify organizational knowledge in reference service (Jantz, 2001).

\section{The Ready Reference Database as Codified Knowledge}

The ready reference database (RRD) is both a knowledge repository as well as a knowledge map. In other words, it contains knowledge (a repository) but it also points to knowledge (a knowledge map). Davenport and Prusak (1998) write that knowledge maps 
often point to both people and documents. These maps are guides that help to locate important information in the organization.

A related process in knowledge creation is "knowledge linking," where information created by other organizations is utilized (Choo, 1998, pp. 134-135). In the ready reference database, this is accomplished through external links to relevant Web sites, embedded information drawn from outside sources, and referrals to outside experts.

Subject guides, database descriptions, Web pathfinders, and library catalogs can all be useful tools in reference. However, these resources are often either too large or too diffuse to be of much help during the time-limited reference interview. The RRD, on the other hand, is codified as a brief yet complete guide to a myriad of potential questions that might be asked of the reference librarian. This is especially true when the question comes out of a domain unfamiliar to the librarian. The RRD is conceived and structured in a way that attempts to mirror the types of questions that might be asked. Thus, it might be analogous in some ways to an expert system.

An important part of the process of leveraging knowledge from an organization is the development of a threefold semantic system of a browseable structure using controlled vocabulary; a syndetic structure utilizing meaningful and usable cross-references; and a powerful search engine that can search keywords in the database repository (Davenport and Prusak, 1998; Choo, 2000). A good ready reference database for libraries will offer 
all of these features. An online thesaurus is ideal in this knowledge environment, but may not always be feasible to create or maintain.

The technology platform of choice for the ready reference database should generally be the Internet. Most libraries will want to use this platform since it requires no special hardware or software and “allows for anytime, anywhere access” (Kesner, 2001b, p. 22). Given the remote nature of modern reference practice, including email digital reference and online chat reference, Internet access to a ready reference database will be preferred by most librarians. Some libraries may want to consider limiting access to librarians and staff if sensitive information (such as passwords) exists in the knowledge repository. But most libraries will not need to create such barriers; freedom of access to information is foundational to both librarianship and knowledge management.

The RRD is a beneficial tool for the reference librarian in many ways. Librarians at the reference desk may decide to print out a copy of a particular RRD entry to provide the patron with an instant finding aid to his or her topic. Librarians working in digital reference, whether online chat or email, may effortlessly copy and paste Web links and reference sources for the patron. Given the variety of contexts in which the RRD might be used, it would appear to be a potentially powerful and useful tool for both novice and experienced reference librarians alike. 


\section{A Test Case for Reference Knowledge Conversion}

The Web-based ready reference database at the San Diego State University Library is a prime example of how tacit knowledge in library reference departments can be made explicit and codified. San Diego State University (SDSU) is one of the largest campuses in the California State University system, with over 30,000 students and 150 academic degree programs. The SDSU Library Reference Services Division consists of one primary service point in the library (as a result of a recent merger which subsumed the Government Documents Reference Division and the Science Reference Division), staffed by sixteen reference librarians with assistance from librarians from other units. There is also an information desk nearby which is staffed by paraprofessionals. In addition to regularly staffed hours at the reference desk (normally by two librarians but during peak hours by three librarians), the Reference Services Division librarians handle a variety of other tasks that require access to a reference knowledge base, including library instruction, individual tutorials, outreach, email reference, phone reference, and online chat reference. Non-reference librarians also perform reference activities on occasion, such as cataloging librarians with subject expertise or archives and manuscripts librarians handling specialized research questions.

At SDSU, "tacit to tacit” knowledge transfer, often called socialization, takes place at the reference desk and in other venues inside and outside of the library. This "behind the scenes” process is vital to the knowledge creation enterprise; while it is not documented and is rarely discussed, tacit to tacit knowledge transfer lays a solid foundation for the 
later stages of knowledge articulation in any library, and the SDSU environment is no exception.

“Tacit to explicit” knowledge transfer, often called articulation or internal codification, takes place in diverse ways at SDSU. Librarians articulate their knowledge and expertise to their colleagues through a variety of means, including in-house training sessions, reference desk interaction, printed lists of new reference sources, emails, reference division meetings, and printed and Web-based research guides. In addition, the RRD project leader elicits knowledge from different sectors through both formal and informal queries and interviews. All of these methods go beyond the foundational "tacit to tacit" knowledge creation process by constructing a permanent or semi-permanent record (through notes, handouts, emails, etc.) of the newly formed explicit knowledge. This knowledge is shared and usable but has not yet been systematically articulated for the purpose of retrieval.

The third level of managing knowledge in the reference department at SDSU is the process of “explicit to explicit” knowledge conversion. The RRD project leader is responsible for expediting this part of the process, which involves the following steps. First, the project leader acquires newly discovered explicit knowledge through emails, listservs, public announcements, private communication, personal observation, and published library guides. This aspect has been described as "warehousing” in the literature of knowledge management (Choo, 2000). 
Second, he gathers the information together and refines the information into a more usable format through extraction of important content and elimination of less crucial data. Often a determination of value must be made in terms of potential usage by reference librarians. The project leader seeks not to duplicate bibliographic guides produced by other librarians, but instead seeks to highlight important aspects from these guides and to fill in gaps created by the absence of guides in certain disciplines. He attempts (at this stage) to anticipate what reference librarians will encounter in the reference interview, based on personal experience, conversations with colleagues, recommendations from other librarians, and literature reviews. This process has been labeled as the "refinery" step of knowledge conversion (Zack, 1999), and includes the initial creation of the codified knowledge as well as ongoing maintenance of the information.

Third, the project leader adapts the "refined knowledge” for use in a technological delivery platform that in the case of SDSU is the Web-based ready reference database. The project leader must ensure that appropriate cross-references, a browseable semantic configuration, and an appropriate search engine are all utilized as part of this infrastructure.

The fourth level of knowledge management in the SDSU Library Reference Division is “explicit to tacit” knowledge conversion, which is sometimes called internalization. This process results in reference knowledge being distributed throughout the reference division and often throughout the entire library. It demands “marketing” of the database by the project leader (through regular emails, announcements at meetings, training 
sessions, etc.) as well as full participation in all aspects of knowledge management by reference librarians and other key library staff.

\section{Analysis}

The SDSU Library Web-based ready reference database contains numerous types of entries which reflect the wide range of knowledge that has been codified. The entries include the following categories:

- Fact-based questions which may be difficult to answer using traditional print or Internet sources

- Demographic or statistical information finding aids (such as health statistics resources or tools for finding historical statistics)

- Detailed analysis of local newspaper holdings in both online and print formats

- Business-related questions (such as consumer behavior or business case studies; over 80 entries in the database are related to business or finance, one of the most popular majors on campus)

- Common term paper questions (such as controversial topics or specific holidays) 
- Internal library questions (such as availability of supplies or color printing)

- Reference Desk issues (responding to phone messages, computer service requests for public workstations, circulating of reference books)

- SDSU Library-generated indexes (local Grand Jury Reports, contents of pamphlet file, etc.)

- Campus information (counseling centers on campus, university yearbooks, alumni directories, and student organizations)

- Class-related assignments

- Subject-based entries (literary criticism, plot summaries, lesson plans, teacher certification)

- Generic questions (acronyms and abbreviations, primary sources, book reviews)

- International topics (embassies and consulates, business cultural practices)

- Student concerns (college ranking, financial aid, fraternities and sororities, tutoring) 
- Common faculty questions (acceptances rates for journals and journal citation reports)

- Commonly requested reference tools (almanacs, dictionaries, atlases)

- Local questions (bookstores, radio and television stations, newspapers, local history)

- State information (state budget, state demographics, state-supported schools)

In addition to categorizing by type of entry, the RRD can also be classified by the different kinds of resources contained therein. These include citations to reference books, links to internal or external Web pages, relevant databases, suggested LCSH subject headings, citations to specific journal articles, facts about the university, phone numbers or addresses, and cross references.

One of the most commonly used types of knowledge contained in this database is citations to reference books. While information about reference books is accessible through the Library’s online catalog, many specialized kinds of information found in reference books are difficult to locate. Subject specialists may already have this knowledge, but the RRD makes it much more accessible to general reference librarians. Annotations for reference books are common in the RRD, as are direct links to the 
Library’s online catalog. Sometimes specific page numbers and instructions on using the reference tool are also included.

Another common feature of the RRD is links to internal or external Internet Web sites. These include free Web pages, premium (passworded) Web sites, internal library Web pages, library pathfinders or subject guides, campus Web pages, and subscription databases. While some of these links are fairly permanent, many of them need maintenance on a regular basis because of URL changes. The project director provides link checking on a regular basis to prevent "link rot.”

An important aspect of many RRD entries at the SDSU Library is suggested LCSH subject headings (with embedded links to the library catalog). These can be very useful to reference librarians who may be unfamiliar with the proper subject heading for a particular topic. For example, a new librarian may not realize that the LCSH heading for Native American historical primary documents is "Indians of North America - History Sources.”

The RRD also contains several entries that have specific citations to journal articles. The $\mathrm{RRD}$ is not meant to replace an appropriate literature search in any of our databases, but there are occasions when specific references are not easily accessible from the literature and may be valuable additions to the knowledge base of the RRD. 
Specific facts, especially those related to the history of the university, are included in the RRD. Some of these "factoids" include information about the "fight song" of the university's athletic teams, the color of hoods that faculty from different departments wear at graduation, and a short description of the Library's history. However, these "fact-based" pieces of knowledge are rare in the RRD. More common is a link to the information found on another Web site or in an authoritative reference source.

Phone numbers and addresses of individuals, departments, libraries, and organizations are occasionally found in the RRD. These are quite useful when the SDSU Library does not own or have access to certain information and must make a referral to an expert or to a specialized organization. Often URLs are provided with phone numbers to facilitate regular updates of the information listed. One example of this type of "knowledge" is in the entry on genealogy. The SDSU Library does not provide genealogical reference service, but we do list the mailing addresses of potential referrals (primarily local genealogical associations).

Cross referencing is an integral and vital part of the RRD. Many entries in the RRD have at least one cross reference; several entries have multiple "see also" references. This syndetic structure is a key part of knowledge retrieval in the ready reference database environment (Stover and Grassian, 1989). 
Finally, each entry in the RRD has the initials of the contact person for that specific piece of knowledge, as well as the date that it was last updated. Both of these facets of the database facilitate efficient maintenance of entries on a regular basis.

Many items formerly included in the RRD have been discarded, primarily because this "knowledge" is available on the Web today in various formats. These pieces of information include names and addresses of professional or student associations, special collections on campus, university rules and policies, full-texts of speeches or songs, definitions of terms, acronyms, and biographical information. All of these types of information can easily be found through Internet search engines and are no longer appropriate for inclusion in the RRD.

\section{Conclusion}

Further research in this area might include a quantitative study of a large number of libraries that employ ready reference databases, or a qualitative analysis of a smaller number of libraries. Researchers may want to investigate some of the barriers that reference librarians face in constructing these types of databases, including personal issues (e.g., are there difficulties in getting reference librarians to articulate their tacit knowledge?) and political issues (e.g., do some members of the reference staff want to keep their tacit knowledge private so as not to endanger their position or prestige within the organization?). This article primarily examined two steps in the knowledge transformation process (“tacit to explicit” and “explicit to explicit”), but other steps in 
this process, such as the "tacit to tacit" stage or the "explicit to tacit" stage, should also be explored by library researchers.

The Web-based ready reference database has the potential to become a highly effective tool when it incorporates knowledge management principles of converting tacit knowledge to explicit, codified knowledge. Reference librarians should be aware of possible problems with codified knowledge as it exists in the ready reference database. Tacit knowledge is difficult to codify due to various obstacles, such as passivity or perceived lack of benefits. Once it is formalized, knowledge can easily become fossilized if not examined and maintained on a regular basis. Codified knowledge should never "trump” tacit knowledge and should not be seen as a replacement or replication of tacit knowledge. But these are all caveats that should not allow us to lose sight of the essential usefulness of explicit, formalized knowledge in library reference service. The codified knowledge of the Web-based ready reference database can be utilized in powerful ways by reference librarians, both in traditional settings at the reference desk (including face to face and telephone reference), as well as in the newer environments of email reference and online chat reference service. 


\section{References}

Angeles, M. (2003), “K-logging: supporting KM with Web logs”, Library Journal NetConnect, Vol. 128 No. 7, pp. 20-22.

Applen, J.D. (2002), “Tacit knowledge, knowledge management, and active user participation in website navigation”, IEEE Transactions on Professional Communication, Vol. 45 No. 4, pp. 302-306.

Baumard, P. (1999), Tacit Knowledge in Organizations, Sage Publications, Thousand Oaks, CA.

Blair, D.C. (2002), “Knowledge management: hype, hope, or help?”, Journal of the American Society for Information Science and Technology, Vol. 53 No. 12, pp. 1019-1028.

Choo, C.W. (2000), "Working with knowledge: how informational professionals help organisations manage what they know”, Library Management, Vol. 21 No. 8, pp. 395-403.

Crowley, B. (2001), “Tacit knowledge, tacit ignorance, and the future of academic librarianship”, College \& Research Libraries, Vol. 62 No. 6, pp. 565-584.

Davenport, T.H. and Prusak, L. (1998), Working Knowledge, Harvard Business School Press, Boston.

Davenport, T.H., Thomas, R.J., and Desouza, K.C. (2003), “Reusing intellectual assets”, 
Industrial Management, Vol. 45 No. 3, pp. 12-17.

Desouza, K.C. (2003), “Facilitating tacit knowledge exchange”, Communications of the ACM, Vol. 46 No. 6, pp. 85-88.

Firestone, J.M. and McElroy, M.W. (2003), Key Issues in the New Knowledge Management, Butterworth-Heinemann, Boston.

Hislop, D. (2002), “Mission impossible? Communicating and sharing knowledge via information transfer”, Journal of Information Technology, Vol. 17, pp. 165-177.

Kesner, R.M. (2001a), “Preparing for knowledge management: part 1, process mapping”, Information Strategy, Vol. 19 No. 1, pp. 7-17.

Kesner, R.M. (2001b), “Preparing for knowledge management: part 2, constructing a KM platform”, Information Strategy, Vol. 18 No. 1, pp. 18-29.

Koenig, M.E.D., and Srikantaiah, T.K. (2000), “The evolution of knowledge management”, in Srikantaiah, T.K. and Koenig, M.E.D., (Eds.), Knowledge Management for the Information Professional, American Society for Information Science, Medford, NJ.

Laupase, R. (2003), “Rewards: do they encourage tacit knowledge sharing in management consulting firms?”, in Coakes, E., (Ed.), Knowledge Management: Current Issues and Challenges, IRM Press, Hershey, PA, pp. 92-103.

Lave, J. and Wenger, E. (1991), Situated Learning: Legitimate Peripheral Participation, Cambridge University Press, New York. 
McInerney, C. (2002), “Knowledge management and the dynamic nature of knowledge”, Journal of the American Society for Information Science and Technology, Vol. 53, No. 12, pp. 1009-1018.

Nonaka, I., Konno, N. and Toyama, R. (2001), “Emergence of "Ba": a conceptual framework for the continuous and self-transcending process of knowledge creation”, in Nonaka, I. and Nishiguchi, T., (Eds.), Knowledge Emergence: Social, Technical, and Evolutionary Dimensions of Knowledge Creation, Oxford University Press, New York, pp. 13-29.

Nonaka, I. and Takeuchi, H. (1995), The Knowledge-Creating Company: How Japanese Companies Create the Dynamics of Innovation, Oxford University Press, New York.

Polanyi, M. (1958), Personal Knowledge: Towards a Post-Critical Philosophy, University of Chicago Press, Chicago.

Polanyi, M. (1966), The tacit dimension, Doubleday, Garden City, NY.

Reber, A.S. (1993), Implicit Learning and Tacit Knowledge: An Essay on the Cognitive Unconscious, Oxford University Press, New York.

Schon, D.A. (1983), The reflective practitioner: how professionals think in action, Basic Books, New York.

Shearmur, J. (2000), “The use of knowledge in organizations: a preliminary exploration”, Knowledge, Technology, and Policy, Vol. 13 No. 3, pp. 30-48. 
Short, T. (2000), "Components of a knowledge strategy: keys to successful knowledge management”, in Srikantaiah, T.K. and Koenig, M.E.D., (Eds.), Knowledge Management for the Information Professional, American Society for Information Science, Medford, NJ.

Smith, E.A. (2001), “The role of tacit and explicit knowledge in the workplace”, Journal of Knowledge Management, Vol. 5 No. 4, pp. 311-321.

Stenmark, D. (2002), "Sharing tacit knowledge: a case study at Volvo”, in Barnes, S., (Ed.), Knowledge Management Systems: Theory and Practice, Thomson Learning, London, pp. 36-48.

Sternberg, R.J. (1999), “What do we know about tacit knowledge? making the tacit become explicit”, in Sternberg, R.J. and Horvath, J.A., (Eds.), Tacit Knowledge in Professional Practice: Researcher and Practitioner Perspectives, Erlbaum, Mahwah, NJ, pp. 231-236.

Sternberg, R.J. and Horvath, J.A. (1999), Tacit Knowledge in Professional Practice: Researcher and Practitioner Perspectives, Erlbaum, Mahwah, NJ.

Stover, M. and Grassian, E. (1989), “Toward an automated reference information system: Inmagic and the UCLA ready-reference information files”, RQ, Vol. 28 No. 4, pp. 517-527.

Thomas, J.E. and Sottong, S.P. (1994), “Automating your ready-reference file”, Reference Services Review, Vol. 22 No. 1, pp. 89-93. 
Wenger, E. (2003), “Communities of practice and social learning situations”, in Nicolini, D., Gheradi, S., and Yanow, D, (Eds), Knowing in Organizations: A PracticeBased Approach, M.E. Sharpe, Armonk, NY, pp. 76-99.

Zack, M.H. (1999), “Managing codified knowledge”, Sloan Management Review, Vol. 40 No. 4, pp. 45-58. 